\title{
Weld Penetration and Marangoni Convection with Oxide Fluxes in GTA Welding
}

\author{
Shanping Lu, Hidetoshi Fujii, Hiroyuki Sugiyama, Manabu Tanaka and Kiyoshi Nogi \\ Joining and Welding Research Institute, Osaka University, Ibaraki, Osaka 567-0047, Japan
}

Active flux can modify the fusion zone geometry dramatically in GTA welding (A-TIG). In the present study, in order to investigate the effect of the active flux on the Marangoni convection in the welding pool, bead-on-plate specimens are made on SUS304 stainless steel pre-placed with single active flux, $\mathrm{Cu}_{2} \mathrm{O}, \mathrm{NiO}, \mathrm{Cr}_{2} \mathrm{O}_{3}, \mathrm{SiO}_{2}$ and $\mathrm{TiO}_{2}$ by the GTA process. Weld pool cross-sections and the bead surface morphology are analyzed by optical microscopy after welding. The oxygen content in the weld metal is measured using a HORIBA EMGA520 Oxygen/Nitrogen Analyzer. The results showed that the depth/width ratio of the weld pool was closely related to the oxygen content in the pool. The oxygen content in the weld metal increases with the quantity of fluxes, $\mathrm{Cu}_{2} \mathrm{O}, \mathrm{NiO}_{2} \mathrm{Cr}_{2} \mathrm{O}_{3}, \mathrm{SiO}_{2}$ and $\mathrm{TiO}_{2}$. $\mathrm{However}$, for the $\mathrm{TiO}_{2}$ oxide flux, the highest oxygen content in the weld metal is below $200 \mathrm{ppm}$. As the oxygen content in the weld metal is in a certain range of 70-300 ppm, the depth/width ratio increases to 1.5 to 2.0 times. Too low or too high oxygen content in the pool does not increase the depth/width ratio. The oxygen from the decomposition of the flux in the welding pool alters the surface tension gradients on the weld pool surface, and hence, changes the Marangoni convection direction and the weld pool penetration depth.

(Received August 19, 2002; Accepted October 3, 2002)

Keywords: gas tungsten arc welding, weld penetration, Marangoni convection, oxide flux, oxygen content

\section{Introduction}

Gas tungsten arc welding has been widely used in industry especially for stainless steel, titanium alloys and other nonferrous metals for high quality welds. However, the shallow penetration restricts its ability to weld thicker structures in a single pass, thus making the productivity relatively low. Recently, a novel modification of the TIG process, active flux TIG (A-TIG), has been brought to many researchers' attention. The simple process of A-TIG, first proposed by the E.O. Paton Institute of Electric Welding in the 1960s, ${ }^{1)}$ can improve the welding pool penetration significantly by preplacing or brushing a thin layer of active flux on the surface of the substrate. Many investigations on the mechanism of the A-TIG process have been made and the two representative theories are arc constriction ${ }^{2-10)}$ and reversal of the Marangoni convection in the welding pool. ${ }^{4,11-14)}$ Sire $^{8)}$ proposed another new technique, called flux bounded TIG (FBTIG). The flux was pre-placed on the two sides near the bead for enhancing the weld penetration before the welding. However the mechanism of FBTIG is not clear. Heiple and Roper had done many research studies on the minor elements' effect on the Marangoni convection in the welding pool. ${ }^{11,12,14)}$ Their results showed that the active elements, such as $\mathrm{O}, \mathrm{S}$ and $\mathrm{Se}$, in the welding pool changed the coefficient of the surface tension to temperature, $\partial \gamma / \partial T$, from negative to positive, and hence reversed the Marangoni convection direction from outward to inward. As the convection was inward, the penetration was increased dramatically. However, there is still no common agreement about the ATIG mechanism.

Together with the experimental investigation, simulation analysis of the welding pool convection and its effect on the penetration was studied by Kou, ${ }^{15-17)}$ Tsai $^{18,19)}$ and Oreper. ${ }^{20)}$ The results also showed that welding pool convection by the surface tension and electromagnetic force were the main driving forces, and the active elements will change the Marangoni convection direction and penetration.
In this study, the emphasis lies in the effect of a single oxide flux on the penetration and oxygen content in the weld pool after welding. Also, the effect of the quantity of flux on the penetration was investigated systematically. Based on these results, the mechanism for A-TIG was discussed.

\section{Experimental Procedure}

A bead-on-plate weld was made on a SUS304 stainless steel substrate machined into rectangular plates, $100 \mathrm{~mm} \times 50 \mathrm{~mm} \times 10 \mathrm{~mm}$, with the average composition of $0.06 \% \mathrm{C}, 0.44 \% \mathrm{Si}, 0.96 \% \mathrm{Mn}, 8.19 \% \mathrm{Ni}, 18.22 \% \mathrm{Cr}, 0.027 \% \mathrm{P}$, $0.001 \% \mathrm{~S}, 0.0016 \% \mathrm{O}$ and the rest of $\mathrm{Fe}$. The oxide fluxes used in the experiment were $\mathrm{Cu}_{2} \mathrm{O}, \mathrm{NiO}, \mathrm{Cr}_{2} \mathrm{O}_{3}, \mathrm{SiO}_{2}$ and $\mathrm{TiO}_{2}$ powders with the specific surface areas shown in Table 1. Before welding, the substrate surface was ground using $80 \#$ abrasive paper and one $100 \mathrm{~mm} \times 5 \mathrm{~mm} \times 0.1 \mathrm{~mm}$ slot was planed on the surface center of the substrate as shown in Fig. 1. The flux was manually pre-placed in the slot over a $50 \mathrm{~mm}$ length and uniformly dispersed with acetone.

Welding was carried out using a DCEN power supply TIG welding with a mechanized system in which the test piece was moved at a constant speed under the TIG torch. Table 2 shows the welding parameters used in the trial.

After welding, the surface morphology and the crosssection of the bead etched by $\mathrm{HCl}+\mathrm{Cu}_{2} \mathrm{SO}_{4}$ solution were photographed by optical microscopy (OLYMPUS HC300Z/OL). The depth/width ratio of the weld $(D / W)$ was

Table 1 Oxides' specific surface area.

\begin{tabular}{lc}
\hline Oxide & Specific surface area $\times 10^{3}\left(\mathrm{~m}^{2} / \mathrm{L}\right)$ \\
\hline $\mathrm{Cu}_{2} \mathrm{O}$ & 2.7 \\
$\mathrm{NiO}$ & 6.6 \\
$\mathrm{Cr}_{2} \mathrm{O}_{3}$ & 3.2 \\
$\mathrm{SiO}_{2}$ & 1.8 \\
$\mathrm{TiO}_{2}$ & 3.5 \\
\hline
\end{tabular}


measured. The oxygen content in the weld metal was analyzed by an oxygen/nitrogen analyzer (HORIBA, EMGA520). Samples for the oxygen measurement were prepared as follows: first of all, the slag on the bead surface was removed by $400 \#$ abrasive paper grinding, and then the weld metal was cut out directly as the oxygen analysis specimen for the bead welded at $160 \mathrm{~A}$. Since the size of the weld manufactured at $80 \mathrm{~A}$ is too small to be cut directly, we cut out the weld metal together with the substrate around the weld, and measured the average oxygen content in the specimen. Based on the volume

Table 2 Welding parameters.

\begin{tabular}{ll}
\hline \multicolumn{1}{c}{ Parameters } & \multicolumn{1}{c}{ Value } \\
\hline Electrode type & DCEN, W-2\% $\mathrm{ThO}_{2}$ \\
Diameter of electrode & $1.6 \mathrm{~mm}$ \\
Vertex angle of electrode & $60^{\circ}$ \\
Shield gas and flow rate & $\mathrm{Ar}, 10 \mathrm{~L} \cdot \mathrm{min}^{-1}$ \\
Arc length & $3 \mathrm{~mm}$ \\
Bead length & $50 \mathrm{~mm}$ \\
Spot time & $3 \mathrm{~s}$ \\
Welding current & $80 \mathrm{~A}, 160 \mathrm{~A}$ \\
Welding speed & $2 \mathrm{~mm} / \mathrm{s}$ \\
\hline
\end{tabular}
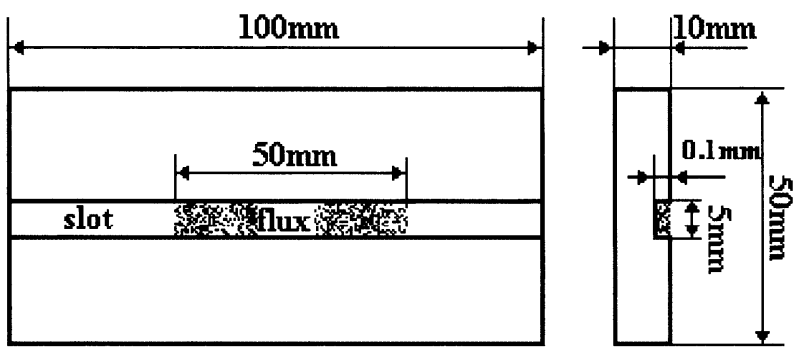

Fig. 1 Schematic of the SUS304 plate used in GTAW.

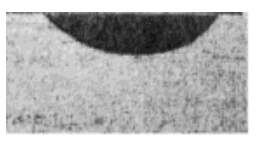

(a) $80 \mathrm{~A} \quad 1 \mathrm{~mm}$

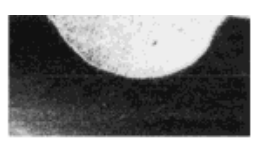

(b) $160 \mathrm{~A} \quad 2 \mathrm{~mm}$
Fig. 2 Weld cross-section without flux. (a) $80 \mathrm{~A}$, (b) $160 \mathrm{~A}$. ratio of the weld metal in the specimen, the oxygen content in the weld metal was then calculated.

\section{Results and Discussion}

\subsection{Weld cross-sections}

Cross-sections of the welding beads made using different oxide fluxes of different quantities were photographed. The fusion zone shapes without flux, and with a different single component flux welded at $80 \mathrm{~A}$ and $160 \mathrm{~A}$ are shown in Figs. 2, 3 and 4, respectively. Compared with the fusion zone shape without flux in Fig. 2, all the five oxide fluxes, $\mathrm{Cu}_{2} \mathrm{O}$, $\mathrm{NiO}, \mathrm{Cr}_{2} \mathrm{O}_{3}, \mathrm{SiO}_{2}$ and $\mathrm{TiO}_{2}$, increases the penetration significantly in a certain range of flux quantity. For a selected single flux, Fig. 4 illustrates the large variation in penetration as a result of the different quantities of fluxes used. Except for $\mathrm{TiO}_{2}$, the penetration depth with the other oxides in the experiment increases first, followed by a decrease with the increasing oxide quantity. However, the penetration depth is still deep with the $\mathrm{TiO}_{2}$ flux even at the high quantity of $450 \times 10^{-5} \mathrm{~mol}$, at both $80 \mathrm{~A}$ and $160 \mathrm{~A}$.

\subsection{Weld $D / W$ ratio and oxygen analysis}

Based on the cross-section pictures, the dimensions and depth/width ratio of the fusion zone were calculated for all the samples. After that, the weld was cut out for the oxygen analysis using the HORIBA EMGA-520. The depth/width ratio and oxygen content in the weld after welding are plotted versus the oxygen quantity in the covered flux before welding in Figs. 5 and 6. Since the solidification speed of the small liquid pool is very high, the oxygen in the weld pool cannot flow out too much in the short solidification process. We consider that the oxygen content in the weld metal measured under solid state is nearly same as the oxygen content in the liquid weld pool. It is clear that the weld $D / W$ ratio initially increases sharply, followed by a decrease as the oxygen quantity increases for the $\mathrm{Cu}_{2} \mathrm{O}, \mathrm{NiO}, \mathrm{Cr}_{2} \mathrm{O}_{3}$ and $\mathrm{SiO}_{2}$ fluxes. For the $\mathrm{TiO}_{2}$ flux, the weld $\mathrm{D} / \mathrm{W}$ ratio increases sharply first and then remains nearly constant with the quantity of flux. The measured oxygen value in the weld after welding is increased with the oxide flux quantity covered before welding for the fluxes $\mathrm{Cu}_{2} \mathrm{O}, \mathrm{NiO}$ and $\mathrm{SiO}_{2}$, while for the $\mathrm{Cr}_{2} \mathrm{O}_{3}$ and $\mathrm{TiO}_{2}$, the oxygen content in the weld first increases then remains approximately constant to $500 \mathrm{ppm}$ and $120 \mathrm{ppm}$, respectively. (a)

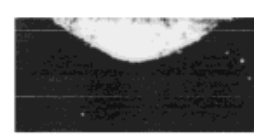

[O] in $\mathrm{Cu}_{2} \mathrm{O} \quad 0.8 \times 10^{-5} \mathrm{~mol}$

(b)

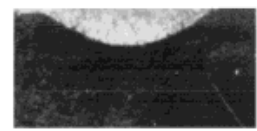

$[\mathrm{O}]$ in $\mathrm{TiO}_{2} \quad 1.0 \times 10^{-5} \mathrm{~mol}$

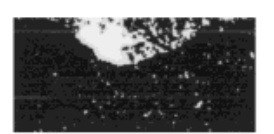

$4.0 \times 10^{-5} \mathrm{~mol}$

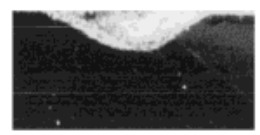

$8.0 \times 10^{-5} \mathrm{~mol}$

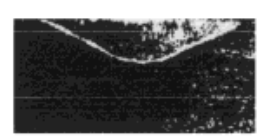

$40 \times 10^{-5} \mathrm{~mol}$

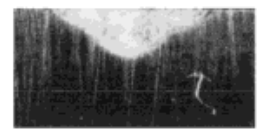

$40 \times 10^{-5} \mathrm{~mol}$

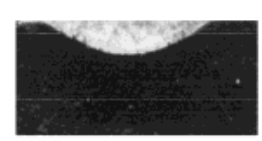

$100 \times 10^{-5} \mathrm{~mol}$

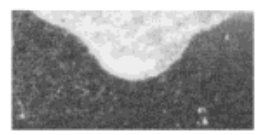

$200 \times 10^{-5} \mathrm{~mol} \quad 1 \mathrm{~mm}$

Fig. 3 Weld cross-sections with $\mathrm{Cu}_{2} \mathrm{O}$ and $\mathrm{TiO}_{2}$ oxide at $80 \mathrm{~A}$. (a) $\mathrm{Cu}_{2} \mathrm{O}$, (b) $\mathrm{TiO}_{2}$. 
(a)
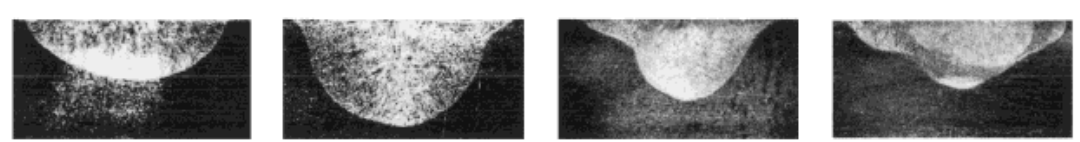

[O] in $\mathrm{Cu}_{2} \mathrm{O}$

$1.0 \times 10^{-5} \mathrm{~mol}$

$16.0 \times 10^{-5} \mathrm{~mol}$

$40 \times 10^{-5} \mathrm{~mol}$

$120 \times 10^{-5} \mathrm{~mol}$

(b)
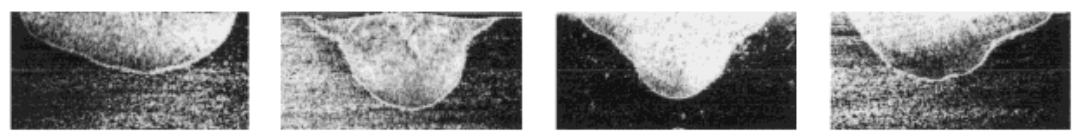

$[\mathrm{O}]$ in $\mathrm{NiO}$

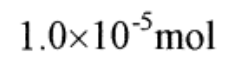

$16.0 \times 10^{-5} \mathrm{~mol}$

$80 \times 10^{-5} \mathrm{~mol}$

$120 \times 10^{-5} \mathrm{~mol}$

(c)
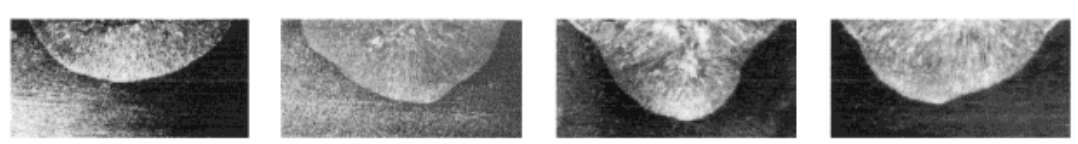

[O] in $\mathrm{Cr}_{2} \mathrm{O}_{3} \quad 1.0 \times 10^{-5} \mathrm{~mol}$

$40 \times 10^{-5} \mathrm{~mol}$

$80 \times 10^{-5} \mathrm{~mol}$

$120 \times 10^{-5} \mathrm{~mol}$

(d)
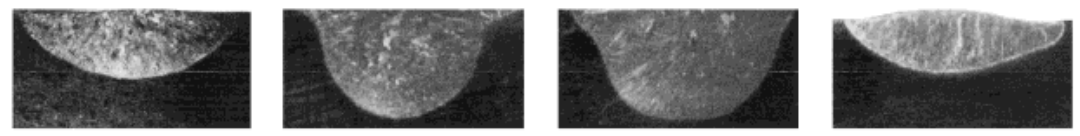

[O] in $\mathrm{SiO}_{2}$

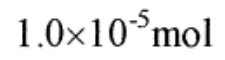

$8.0 \times 10^{-5} \mathrm{~mol}$

$120 \times 10^{-5} \mathrm{~mol}$

$240 \times 10^{-5} \mathrm{~mol}$

(e)
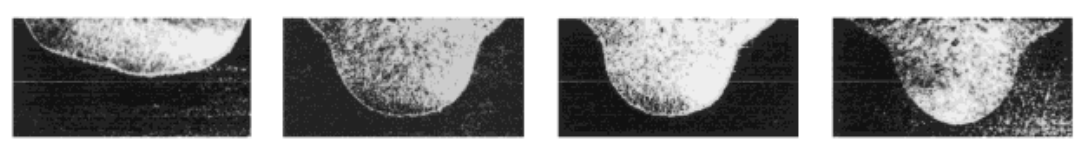

$[\mathrm{O}]$ in $\mathrm{TiO}_{2}$

$1.0 \times 10^{-5} \mathrm{~mol}$

$16 \times 10^{-5} \mathrm{~mol}$

$120 \times 10^{-5} \mathrm{~mol}$

$450 \times 10^{-5} \mathrm{~mol}$

$2 \mathrm{~mm}$

Fig. 4 Weld cross-sections with different oxides at 160 A. (a) $\mathrm{Cu}_{2} \mathrm{O}$, (b) $\mathrm{NiO}$, (c) $\mathrm{Cr}_{2} \mathrm{O}_{3}$, (d) $\mathrm{SiO}_{2}$, (e) $\mathrm{TiO}_{2}$.

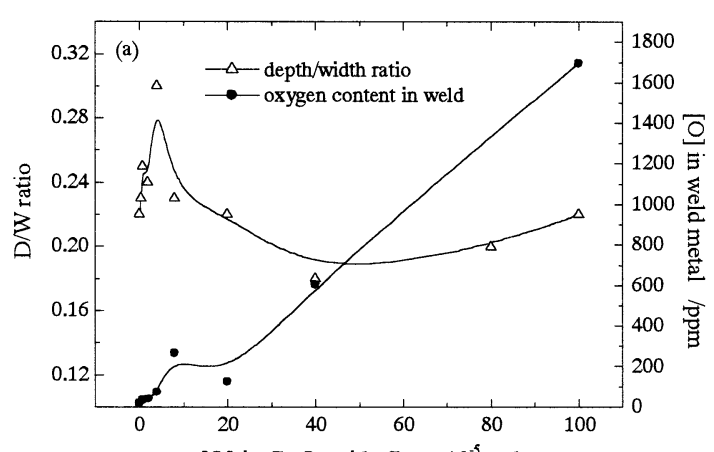

$[\mathrm{O}]$ in $\mathrm{Cu}_{2} \mathrm{O}$ oxide flux $\times 10^{-5} \mathrm{~mol}$

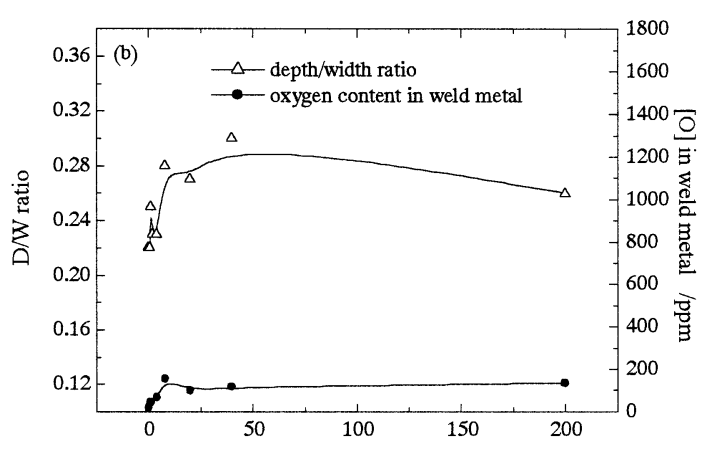

$[\mathrm{O}]$ in $\mathrm{TiO}_{2}$ oxide flux $\times 10^{-5} \mathrm{~mol}$

Fig. $5 D / W$ ratio and oxygen content in weld $v s$. flux quantity at $80 \mathrm{~A}$. (a) $\mathrm{Cu}_{2} \mathrm{O}$, (b) $\mathrm{TiO}_{2}$.

Compared with the $\mathrm{Cu}_{2} \mathrm{O}$ and $\mathrm{NiO}$ fluxes, $\mathrm{Cr}_{2} \mathrm{O}_{3}$ and $\mathrm{TiO}_{2}$ are more stable and hence the decomposition is relatively difficult in the same welding process. Therefore, the oxygen in the weld metal from the decomposition of the flux cannot be increased continuously as $\mathrm{Cu}_{2} \mathrm{O}$ and $\mathrm{NiO}$.

Weld penetration in GTAW was determined by the fluid flow mode in the weld pool, which is driven by the electromagnetic force, surface tension gradient, buoyancy force and impinging force of the arc plasma. Among them, the surface tension gradient on the welding pool surface is the prin- ciple variable that changes the convection mode. Generally, the surface tension decreases with the increasing temperature, $\partial \sigma / \partial T<0$, for pure metal and many alloys. In the weld pool for such materials, the surface tension is higher in the relatively cooler part of the pool edge than that in the pool center under the arc, and hence the fluid flows from the pool center to the edge. The heat flux is easily transferred to the edge and the weld pool shape is relatively wide and narrow as shown in Fig. 7(a). Heiple and Roper ${ }^{12,14,21,22)}$ proposed that surface active elements such as oxygen, sulfur and selenium 

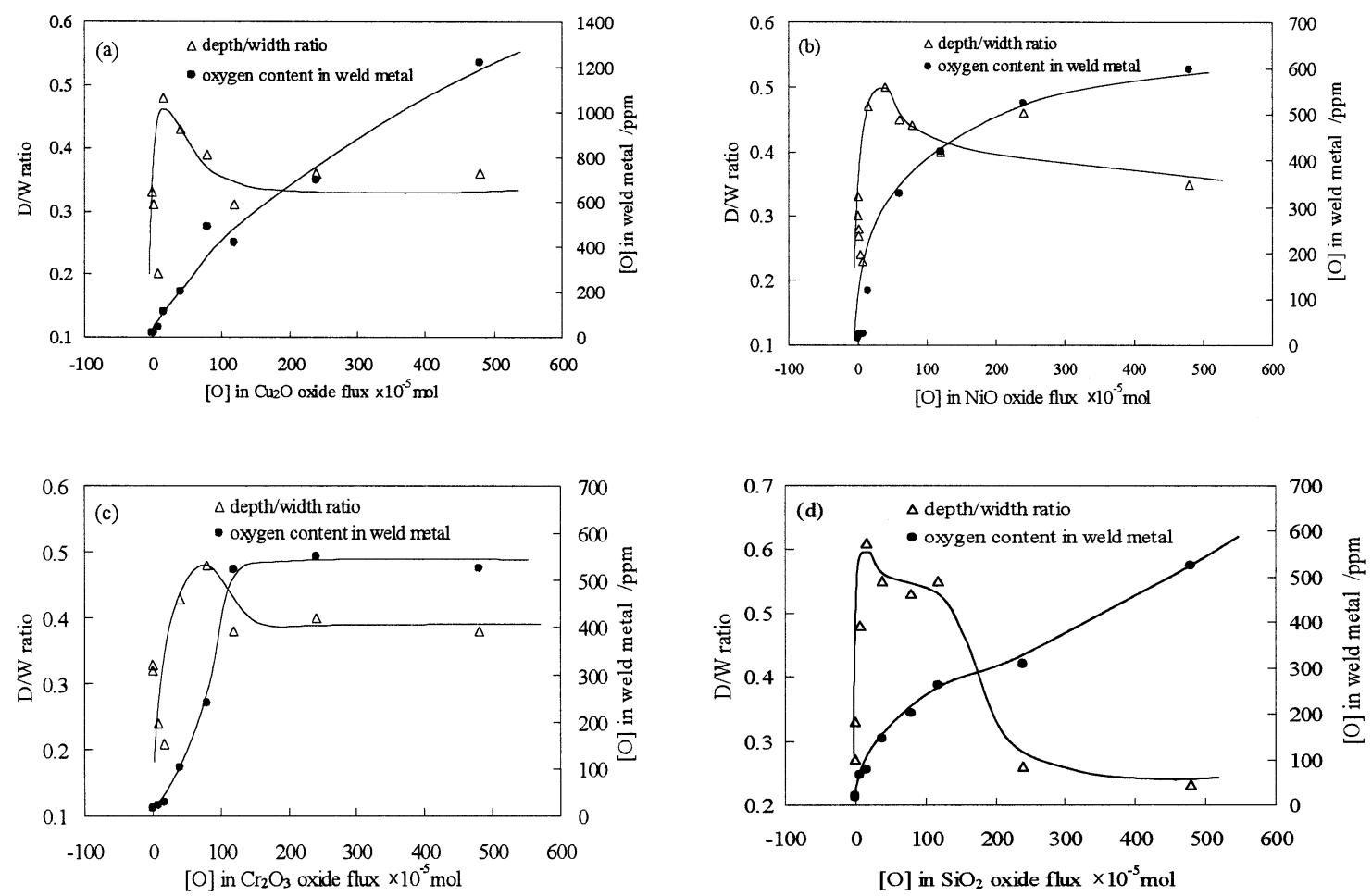

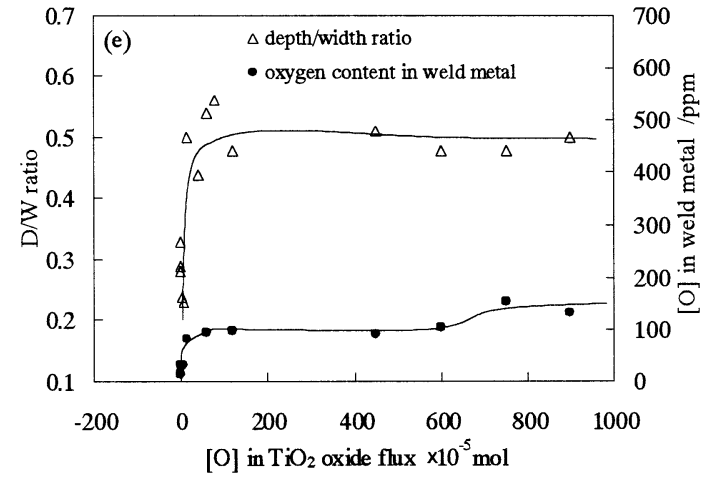

can change the temperature coefficient of the surface tension for iron alloys from negative to positive, $\partial \sigma / \partial T>0$, and further change the direction of the fluid flow in the weld pool as illustrated in Fig. 7(b). In that case, a relatively deep and narrow weld was produced.

In our experiments, the oxygen in the weld from the decomposition of the oxide flux played the important role as an active element and changed the Marangoni convection mode of the liquid weld pool. The conclusion by Taimatsu and $\mathrm{Nogi}^{23}$ ) showed that oxygen was an active element in pure liquid iron in the range of $150-350 \mathrm{ppm}$. In this range, the temperature coefficient of the surface tension of the $\mathrm{Fe}-\mathrm{O}$ alloy is positive, while out of the range, the temperature coefficient of the surface tension became to negative or nearly zero. It can be assumed that the oxygen in the stainless steel weld pool has the same effect. As the oxygen content in the weld increased with the oxide flux quantity, the Marangoni convection mode changes from outward to inward first, and then the inward convection becomes weaker or changed to the outward direction as the oxygen content increases in the weld. For that reason, the $D / W$ ratio increases initially, followed by a decrease with the oxygen in the weld metal as shown in
Fig. $6 D / W$ ratio and oxygen content in weld $v s$. flux quantity at 160 A. (a) $\mathrm{Cu}_{2} \mathrm{O}$, (b) $\mathrm{NiO}$, (c) $\mathrm{Cr}_{2} \mathrm{O}_{3}$, (d) $\mathrm{SiO}_{2}$, (e) $\mathrm{TiO}_{2}$.

Figs. 5 and 6. Since the oxygen in the weld for $\mathrm{TiO}_{2}$ is lower than $200 \mathrm{ppm}$, the penetration does not decrease even when using a large quantity of flux. There are certain quantities of alloy elements such $\mathrm{Ni}$ and $\mathrm{Cr}$ in the stainless steel, which may affect the oxygen range for a positive $\partial \gamma / \partial T$ different from that in the pure iron of $150-350 \mathrm{ppm}$. In our experiments, it is found that when the oxygen content in the weld is in the range of 70-300 ppm, the penetration of the weld pool was deep as shown in Fig. 8.

\subsection{Bead morphology}

Comparing the results of the $\mathrm{Cu}_{2} \mathrm{O}$ flux with that of the $\mathrm{TiO}_{2}$ flux in Figs. 5 and 6, it is found that there is a narrow range for the $\mathrm{Cu}_{2} \mathrm{O}$ quantity for which the $D / W$ ratio was higher than 0.4 , while there is a substantial range of $\mathrm{TiO}_{2}$ quantity $\left([\mathrm{O}]\right.$ in $\left.\mathrm{TiO}_{2}>100 \times 10^{-5} \mathrm{~mol}\right)$ for which the $D / W$ ratio is independent of the $\mathrm{TiO}_{2}$ quantity. This significant difference is related to the chemistry-physical properties of the oxides. As mentioned above, from the Ellingham diagram $\left(\Delta G^{\circ}-T\right)$, the $\mathrm{Cu}_{2} \mathrm{O}$ oxide is unstable and easily decomposed under the arc. The decomposed oxygen would dissolve in the weld pool and quickly increase the oxygen content in the 

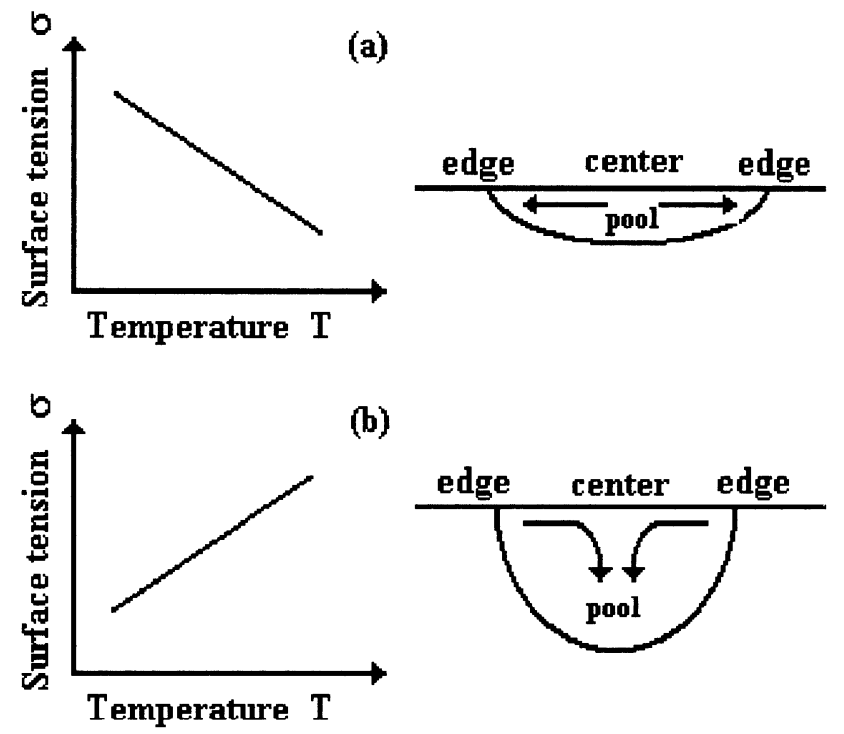
(a) $\frac{\partial \sigma}{\partial T}<0$
(b) $\frac{\partial \sigma}{\partial T}>0$

Fig. 7 Marangoni convection mode by surface tension gradient in welding pool. (a) $\frac{\partial \sigma}{\partial T}<0$; (b) $\frac{\partial \sigma}{\partial T}>0$.

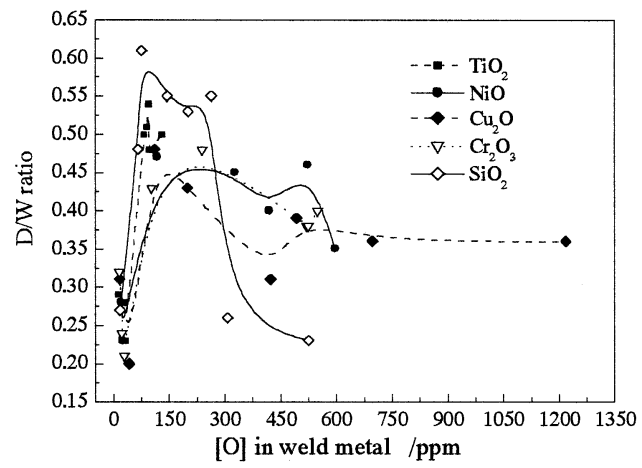

Fig. $8 \quad D / W$ ratio $v s .[\mathrm{O}]$ in weld.

weld. If the oxygen content is too high, the inward Marangoni convection becomes weak or changes to the outward direction and the weld pool penetration decreases again. However, the $\mathrm{TiO}_{2}$ oxide is stable and not decomposed completely under the arc, which caused the oxygen content in the weld pool to be relatively low and the Marangoni convection mode is maintained in the inward direction.

Based on observations of the molten pool surface, as the $\mathrm{TiO}_{2}$ oxide quantity in the $5 \mathrm{~mm} \times 0.1 \mathrm{~mm} \times 50 \mathrm{~mm}$ slot is over $120 \times 10^{-5} \mathrm{~mol}$, the majority of the $\mathrm{TiO}_{2}$ flux melts into a liquid ball just in front of the arc and moves forward together with the arc as shown in Fig. 9. The size of the liquid flux ball increases gradually as the new flux melts. Eventually the liquid ball would be broken under the arc and leave a pit on the bead surface as shown in Fig. 10 (arrow position). Because of this, the majority of $\mathrm{TiO}_{2}$ has no function in increasing the oxygen in the weld. This phenomenon does not exist for the other oxides used in these experiments. From the results, it is shown that deep penetration is not sensitive to

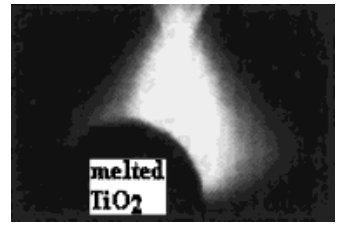

Fig. 9 Molten flux during welding with large quantity of $\mathrm{TiO}_{2}$.

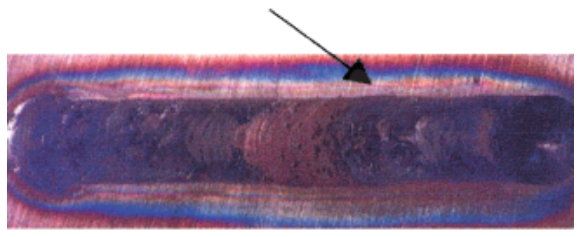

(a)

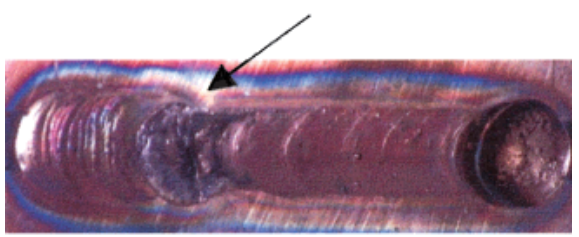

(b)

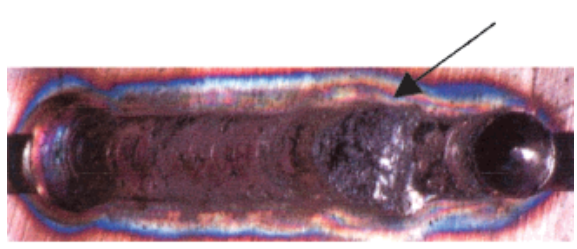

(c)

Fig. 10 Bead morphologies with large quantity of $\mathrm{TiO}_{2}$. (a) $120 \times 10^{-5} \mathrm{~mol}$, (b) $450 \times 10^{-5} \mathrm{~mol}$, (c) $750 \times 10^{-5} \mathrm{~mol}$.

the $\mathrm{TiO}_{2}$ flux quantity covered before welding, but sensitive to the $\mathrm{Cu}_{2} \mathrm{O}$ flux quantity. Therefore, the $\mathrm{TiO}_{2}$ flux is a good recommended active flux in GTAW for deep penetration.

\section{Conclusions}

(1) In GTA welding, the quantity of the oxide flux has a significant effect on the weld penetration. The weld depth/width ratio initially increases, followed by a decrease with the increasing flux quantity for $\mathrm{Cu}_{2} \mathrm{O}, \mathrm{NiO}, \mathrm{Cr}_{2} \mathrm{O}_{3}$ and $\mathrm{SiO}_{2}$.

(2) The oxygen from the decomposition of the flux alters the surface tension gradient on the weld pool surface and hence changes the Marangoni convection direction and the weld pool penetration. As the oxygen content in the weld is in the range of $70-300 \mathrm{ppm}$, the weld depth/width ratio is increased by 1.5 to 2 times. Too low or too high oxygen content in the weld does not increase the depth/width ratio. The Marangoni convection in the welding pool plays an important role in changing the weld pool convection mode and the weld penetration.

(3) The weld $D / W$ ratio is not sensitive to the $\mathrm{TiO}_{2}$ quantity. Therefore, $\mathrm{TiO}_{2}$ is a highly recommended active flux for 
deep penetration for real GTAW applications.

\section{Acknowledgements}

This work is the result of "Development of Highly Efficient and Reliable Welding Technology", which is supported by the new Energy and Industrial Technology Development Organization (NEDO) through the Japan Space Utilization Promotion Center (JSUP) in the program of Ministry of Economy, Trade and Industry (METI).

\section{REFERENCES}

1) S. M. Gurevich and V. N. Zamkov: Avtom. Svarka. 1966 (12), 13-16.

2) P. J. Modenesi, E. R. Apolinario and I. M. Pereira: J of Mater. Proc. Tech. 99 (2000) 260-265.

3) S. Kou and Y. H. Wang: Weldg. J. 65 (1986) 63s-70s.

4) M. Tanaka, T. Shimizu, H. Terasaki, M. Ushio, F. Koshi-ishi and C. L. Yang: Sci. \& Tech. of Weld. \& Join. 5 (2000) 397-402.

5) D. S. Howse and W. Lucas: Sci. \& Tech. of Weld. \& Join. 5 (2000) 189-193.

6) H. C. Ludwig: Weldg. J. 47 (1968) 234s-240s.

7) Ding Fan, Ruihua Zhang, Yufen Gu and M. Ushio: Trans. JWRI. 30
(2001) 35-40.

8) S. Sire and S. Marya: Proc. of the 7th Int. Symp. JWS (2001) pp. 113118.

9) S. Marya and S. Sire: Proc. of the 7th Int. Symp. JWS (2001) pp. 107112.

10) T. Ohji, A. Miyake, M. Tamura, H. Inoue and K. Nishiguchi: J. of Japan Weld. Soc. 8 (1990) 54-58.

11) C. R. Heiple and J. R. Roper: Weldg. J. 61 (1982) 97s-102s.

12) C. R. Heiple, J. R. Roper, R. T. Stagner and R. J. Aden: Weldg. J. 62 (1983) 72s-77s.

13) H. Fujii, N. Sogabe, M. Kamai and K. Nogi: Proc. of the 7th Int. Symp. JWS (2001) pp. 131-136.

14) C. R. Heiple and J. R. Roper: Weldg. J. 60 (1981) 143s-145s.

15) S. Kou and D. K. Sun: Metall. Trans. A. 16 (1985) 203-213.

16) S. Kou and Y. H. Wang: Weldg. J. 65 (1986) 63s-70s.

17) C. Limmaneevichitr and S. Kou: Weldg. J. 79 (2000) 324s-330s.

18) Y. Wang and H. L. Tsai: Metall. Mater. Trans. 32B (2001) 501-515.

19) Y. Wang, O. Shi and H. L. Tsal: Metall. \& Mater. Trans. 32B (2001) $145-161$.

20) G. M. Oreper, T. W. Eagar and J. Szekely: Weldg. J. 62 (1983) 307s$312 \mathrm{~s}$.

21) C. R. Heiple and P. Burgardt: Weldg. J. 64 (1985) 159s-162s.

22) J. R. Roper and D. L. Olson: Weldg. J. 57 (1978) 103s-107s.

23) H. Tamatsu, K. Nogi and K. Ogino: J. High. Temp. Soc. 18 (1992) 1419. 